\title{
Expression and significance of molecular biomarkers in esophageal carcinoma in different nationalities patients in Xinjiang
}

\author{
L. Zhang', J. Sun', J.Q. Zhang ${ }^{3}$, M. Yang ${ }^{3}$, G. Bai ${ }^{3}$ and X.L. Ma ${ }^{1}$ \\ ${ }^{1}$ Department of Internal Medicine, \\ First Affiliated Hospital of Xinjiang Medical University, \\ Urumqi, Xinjiang, China \\ ${ }^{2}$ Department of Hepatopathy, \\ First Affiliated Hospital of Xinjiang Medical University, \\ Urumqi, Xinjiang, China \\ ${ }^{3}$ Cancer Center, First Affiliated Hospital of Xinjiang Medical University, \\ Urumqi, Xinjiang, China \\ Corresponding author: L. Zhang \\ E-mail: zhangli9514@126.com
}

Genet. Mol. Res. 13 (3): 5413-5425 (2014)

Received June 4, 2013

Accepted October 4, 2013

Published July 24, 2014

DOI http://dx.doi.org/10.4238/2014.July.24.21

\begin{abstract}
This study aimed to explore some useful biomarkers to focus on the diagnosis and therapy response judgment in esophageal squamous cell carcinoma in Xinjiang. We used enzyme-linked immunosorbent method and immunohistochemistry to detect the expression of VEGF, EGFR, ES, HER-2, and NF- $\kappa$ Bp in the serum and tissue with esophageal squamous cell carcinoma, and to analyze the relationship between biomarkers and clinical pathology and curative effects. Our findings were as follows: 1. The serum levels of VEGF and ES in Han patients were obviously higher than those of Uygur and Kazakh patients $(\mathrm{P}<0.05)$. The VEGF positive rate in patients at a later clinical stage was higher than that of the patients at an earlier clinical stage (stages II-IV were 14.29, 50.00 , and $50.00 \%$, respectively, $\mathrm{P}<0.05$ ), meanwhile it was higher than
\end{abstract}


that of patients without lymph node metastases $(78.13$ vs $25.00 \%, \mathrm{P}<$ 0.05). The curative effective rate of patients with negative expression of VEGF was higher than that of patients with positive expression of VEGF (74.67 vs $41.40 \%, \mathrm{P}<0.05)$. 2. The expression of EGFR protein in male patients was higher than that of female patients $(69.77$ vs $35.29 \%, \mathrm{P}<$ 0.05). Before treatment, the serum EGFR level in patients was higher than the normal group $(\mathrm{P}<0.05)$. 3. The serum ES level in patients before and after treatment was significantly higher than in the normal group $(\mathrm{P}<$ $0.05)$. 4. The HER-2 positive rate in higher differentiated tumor tissue was lower than that in lower differentiated tumor tissue. (The positive rate of I, II, III grade was $70.00,30.00$, and $20.00 \%$, respectively, $\mathrm{P}<0.05$ ). 5 . The $\mathrm{NF}-\mathrm{\kappa B}$ positive rate in patients with lymph node metastases was higher than that of patients without lymph node metastases (65.63 vs 39.27\%, P $<0.05)$, meanwhile median survival in the latter group was higher than that of the former group $(\mathrm{P}<0.05)$. Our data suggest that the expression of VEGF and ES were different in Uygur, Han, and Kazakh patients in Xinjiang. The combined detection of tumor markers in serum and tissue is of direct significance for tumor therapy.

Key words: Esophageal cancer; Biomarkers; Curative effect; National difference

\section{INTRODUCTION}

In the early 1970s, a study in the former Soviet Union first reported that the incidence of esophageal cancer in Kazakhs was high (Kairakbaev, 1978). In the late 1970s, a cancer census report showed that the incidence of esophageal cancer in Kazakhs in Northwest China was high, and among them, the incidence of esophageal cancer of the Tory family in Tuoli County of the Kazakh Autonomous Prefecture in Xinjiang was the highest in the world (Figure 2; 150/10 million). The second highest was 90/10 million in Xinyuan County. Less than 500 miles south of the Tarim Basin, Tianshan, in the Uygur residence (here after referred to as Uighurs), the incidence rates of esophageal cancer were 11/10 million and 13/10 million in Uighurs and Han. Esophageal cancer is a serious disease affecting the health of ethnic minorities in Xinjiang, resulting in poverty.

Esophageal cancer is a frequent malignancy and cannot be detected early. The survival rate of patients with advanced stage is low (5-year survival, 0-26\%). Because of the lack of early diagnosis, $80 \%$ esophageal cancer patients are at advanced stage when the disease is diagnosed, and they lose the opportunity of radical resection, even if the 5-year survival rate of the patients with surgery (R0; negative surgical margins) is only $15-20 \%$ and the median survival time of the patients is 18 months (Jemal et al., 2004; Ychou et al., 2011). Combination therapy involving radiotherapy and chemotherapy exerts important effects in the comprehensive treatment of esophageal cancer. In treatment, there are "bottleneck" problems at home and abroad; the therapeutic effects of various treatments cannot currently be predicted and they make the treatment of majority of patients with esophageal cancer into a "procedural" or "menu-type" treatment modality and not real individualized treatment protocols (Liu et al., 
2011a). In recent years, research on esophageal cancer in minorities in Xinjiang has focused on the pathogenesis, clinical characteristics, and epidemiology of the disease, and has led to some meaningful results (Lin et al., 2011b).

Recently, the prediction of efficacy and prognosis of diseases at a molecular level has become a hotspot (Luthra et al., 2006; Hildebrandt et al., 2009; Geldart and Astras, 2011). In this study, the expression of epidermal growth factor receptor (EGFR), vascular endothelial growth factor (VEGF), human endothelial cell inhibin (ES), human nuclear factor- $\kappa \mathrm{B}$ (NF$\kappa \mathrm{B}$ ), and epidermal growth factor receptor 2 (HER-2), all of which are related to the proliferation, invasion, angiogenesis, and metastasis of esophageal cancer, was detected by the co-enzyme-linked immunosorbent assay method combined with immunohistochemical detection to explore the relationship between these tumor markers and clinical pathology and the therapeutic effects of esophageal squamous cell carcinoma.

\section{MATERIAL AND METHODS}

\section{Clinical data}

Tissue and blood samples of 128 patients with a definite pathological diagnosis of esophageal squamous cell carcinoma from 2007-2006 to 2010-2011 in the First Affiliated Hospital of Xinjiang Medical University were collected. Patients from Han nationality (44 cases), Uygur (38 patients), and Kazakh (46 patients) were included. The patients included had a similar clinical stage II-IV stage, and distribution of population data (age, gender, race gender, clinical stage, histological type, and general condition score $)(P>0.05)$. Eight-six men and 42 women were enrolled. The median age of patients was 55.8 years. The tumor was in the cervical segment and upper thoracic segment in 48 cases, and in the thoracic middle segment and inferior segment in 80 cases. Stage I 24 cases, stage II 62 cases, stage III 42 cases in the pathological differentiation stage. In clinical stage, stage II 32 cases, stage III 32 cases and stage IV 64 cases. The clinical staging of esophageal cancer was set according to the AJCC staging standard. We included 60 healthy volunteers of all nationalities in the normal control group.

\section{Experimental methods}

\section{Blood collection}

We collected $5 \mathrm{~mL}$ venous blood samples of each patient before and after treatment. After centrifugation, the samples were put into a $-80^{\circ} \mathrm{C}$ refrigerator. The levels of expression of S-EGFR, S-ES, S-VEGF, S-HER2, and S-NF-kB of patients with esophageal squamous cell carcinoma and the normal control group were detected by enzyme-linked immunosorbent assay (ELISA), and the experiment was performed in accordance to the method in the instructions. Finally, the values of S-VEGF, S-EGFR, S-ES, S-HER2, and S-NF- $\mathrm{kBp}$ were calculated according to the standard curve.

\section{Immunohistochemical SP method}

Phosphate buffer (0.01 M PBS), instead of primary antibody, was used as the negative control, and known positive tissue sections were used as the positive control. 


\section{Judgment of immunohistochemical results}

Positive staining for EGFR, HER-2, and ES protein was observed in the cell membrane, while positive staining for VEGF and NF- $\mathrm{kB}$ protein was observed in the cytoplasm. Under a light microscope, 5 high-power fields of each slice were randomly selected, 200 tumor cells in each field of vision were counted, and the number of positive cells was counted to analyze the immunohistochemical expression of EGFR in 1000 tumor cells. When the number of positive cells in the visual field exceeded 5\%, the expression was expressed as positive (+). Otherwise, it was considered to be negative (-).

\section{Evaluation criteria of treatment and therapeutic effect}

Chemotherapy design: bigeminy chemotherapy based on platinum (NP = navelbine + cisplatin/carboplatin, TP = docetaxel/paclitaxel + cisplatin/carboplatin), once every 3-4 weeks, 4-6 times. Radiotherapy: 3-dimensional conformal irradiation, DT50-66GY/25-33f (prophylactic irradiation, $50 \mathrm{GY}$; radical irradiation, 60-66 GY).

Studying short-term therapeutic effect included data about complete remission (CR), partial remission (PR), stability (NC), and progress (PD). CR + PR suggested that the treatment was effective and $\mathrm{NC}+\mathrm{PD}$ suggested that it was inefficient. The median survival time was also calculated.

\section{Statistical methods}

The SPSS13.0 statistical software was used for data processing; of them, $t$-test or analysis of variance was applied for data measurement, chi-square test was applied for data numeration, and survival rates are calculated by the Kaplan-Meier method for survival analysis. The size of test was $\alpha=0.05$ and $\mathrm{P}<0.05$ was considered to be statistically significant.

\section{RESULTS}

\section{Serum levels of molecular markers of patients with esophageal squamous cell carcinoma before and after treatment}

VEGF levels in the serum of patients with esophageal squamous cell carcinoma before the treatment were higher than that of the normal group $(\mathrm{P}<0.05)$. There was no significant difference between the VEGF levels in the serum of patients with esophageal squamous cell carcinoma after treatment and that of the normal group $(\mathrm{P}=0.062)$, while ES levels in the serum of patients with esophageal squamous cell carcinoma before and after treatment were higher than that of the control group $(\mathrm{P}<0.05)$. EGFR levels in the serum of patients with esophageal squamous cell carcinoma before treatment were higher than that of the normal control group $(\mathrm{P}<0.05)$ (Table 1). VEGF and NF-kB levels in the serum of patients with esophageal squamous cell carcinoma after treatment showed no difference compared to that of patients before treatment (data not shown in the table). The levels of serum tumor markers of patients after treatment also showed no significant difference compared to that of patients before treatment $(\mathrm{P}>0.05)$ (Table 1). 


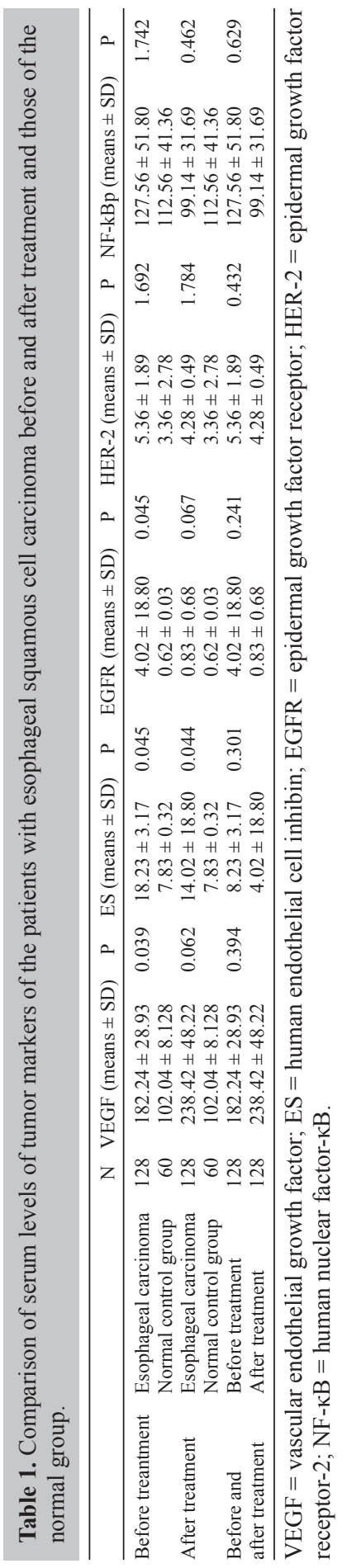




\section{Relationship between the serum molecular markers of patients with esophageal squamous cell carcinoma and nationality}

Serum levels of VEGF and ES in Han patients were obviously higher than those in Uygur and Kazakh patients $(258.48 \pm 39.38$ and $27.88 \pm 43.22 \mathrm{ng} / \mathrm{L}, \mathrm{P}<$ $0.05)$, while those of Uygur patients were the lowest $(106.00 \pm 28.76$ and $8.59 \pm 2.63$ $\mathrm{ng} / \mathrm{L}$ ) (Table 2).

\section{Relationship between tissue protein expression of molecular markers of patients with esophageal squamous cell carcinoma and clinical pathology}

As Table 3 shows, the positive rate of VEGF expression of patients at a later clinical stage was higher than that of patients at an earlier clinical stage (stages II-IV were $14.29,50.00,50.00 \%$, respectively, $\mathrm{P}<0.05$ ). The positive rate of VEGF expression in patients with lymph node metastases was higher than that of patients without lymph node metastases $(78.13$ vs $25.00 \%, \mathrm{P}<0.05)$.

The expression of EGFR in the tumor tissue of male patients was higher than that of female patients $(69.77 v s 35.29 \%, \mathrm{P}<0.05)$. The positive rate of HER-2 expression in higher differentiated tumor tissue was lower than that of HER-2 expression in lower differentiated tumor tissue (the positive rate of I, II, III grade was 70.00, 30.00, and $20.00 \%$, respectively, $\mathrm{P}<0.05$ ). The positive rate of NF- $\mathrm{kBp}$ expression in patients with lymph node metastases was higher than that of patients without lymph node metastases (65.63 vs $39.27 \%, \mathrm{P}<0.05)$. HER-2 expression in the serum had no significant relationship compared to other clinical pathological factors $(\mathrm{P}>0.05)$ (Figure 1).

\section{Relationship between tissue protein expression of molecular markers of patients with esophageal squamous cell carcinoma and short-term therapeutic effect}

There were 53 cases (41.4\%) with VEGF-positive expression and 23 cases (43.4\%) with effective chemoradiotherapy. There were 75 cases $(58.59 \%)$ with VEGF-negative expression and 56 cases $(74.67 \%)$ with effective chemoradiotherapy. The curative effective rate of patients with VEGF-negative expression was higher than that of patients with VEGF-positive expression (74.67 vs 41.40\%, P < 0.05) (Table 4).

Relationship between NF- $\kappa$ Bp expression and median survival time (MST). The MST of patients with negative expression of NF- $\kappa B p$ was higher than that of patients with positive expression of NF-kBp $(26$ months, 20 months, $\mathrm{P}<0.05)$ (Figure 2). 


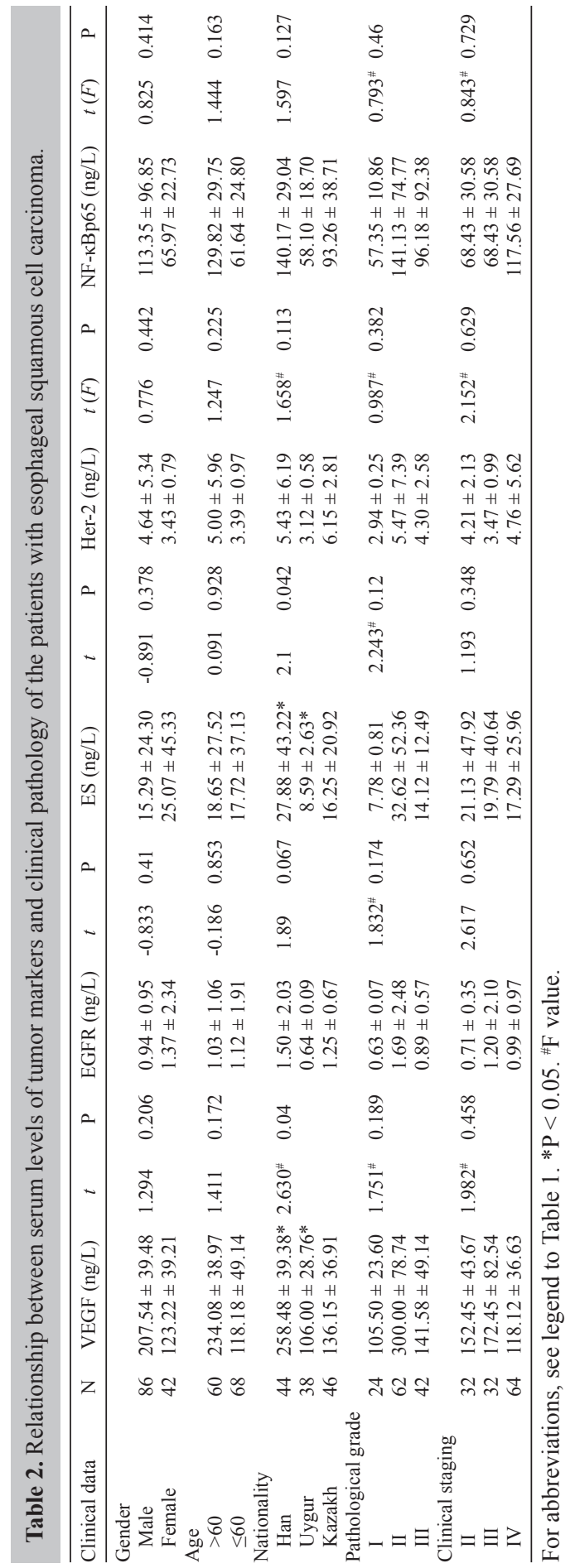


L. Zhang et al.

5420

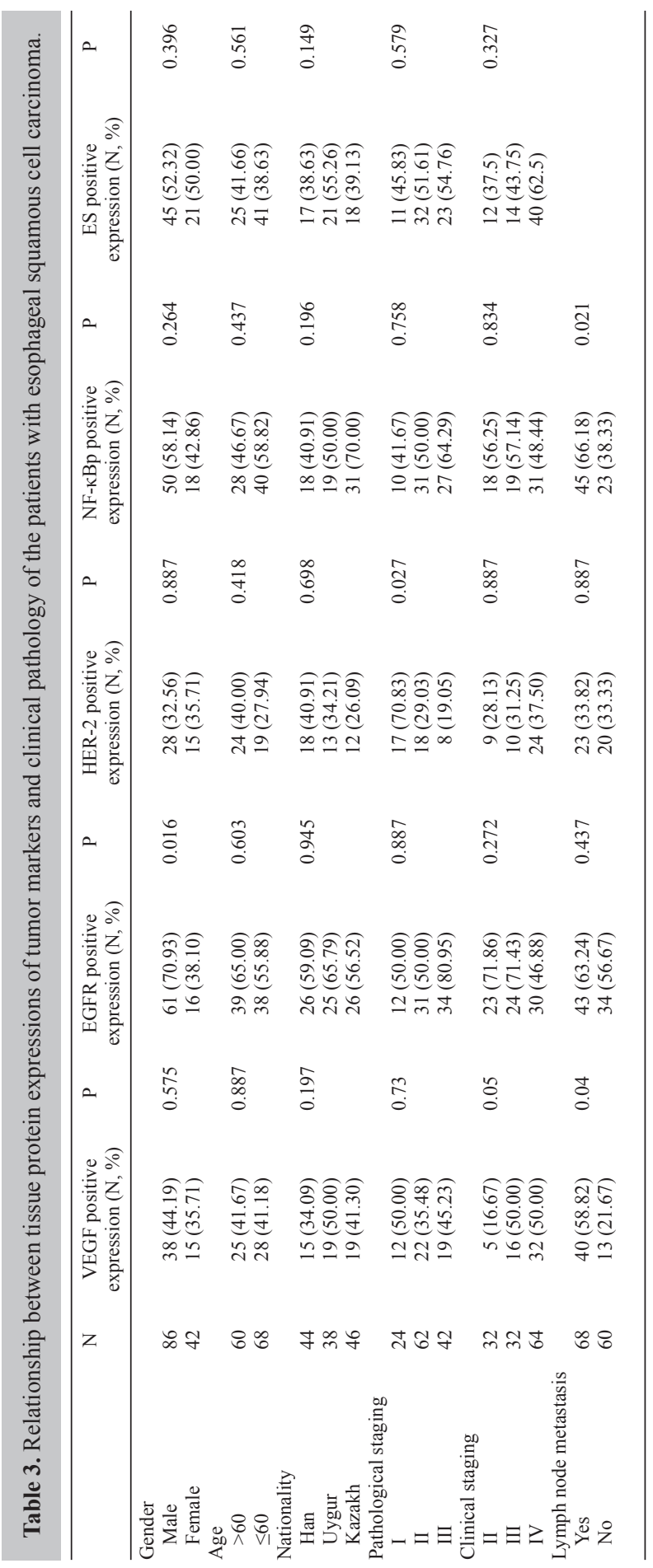

Genetics and Molecular Research 13 (3): 5413-5425 (2014)

CFUNPEC-RP www.funpecrp.com.br 

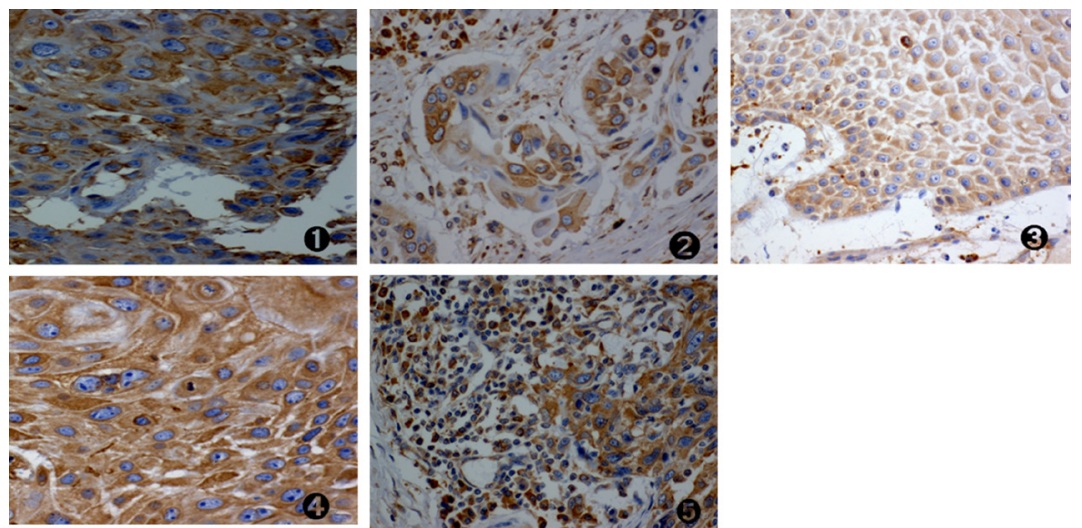

Figure 1. Tissue expressions of tumor molecular markers in the human esophageal squamous cell carcinoma tissues. 1. Esophageal squamous cell carcinoma stained positive for EGFR, located in the cytoplasm and cell membrane, SP stain 200X; 2. ES-positive expression in esophageal squamous cell carcinoma, located in the cell membrane, SP stain 200X; 3. NF- $\mathrm{BBp}$ esophageal squamous cell carcinoma staining, located in the cell membrane, SP stain 200X; 4. esophageal squamous cell carcinoma stained positive for HER-2, located in the cell membrane, SP stain 200X; 5. esophageal squamous cell carcinoma stained positive for VEGF, located in the cell membrane, SP stain 200X.

Table 4. Relationship between the expression of tumor molecular markers of the patients with esophageal squamous cell carcinoma and therapeutic effect.

\begin{tabular}{|c|c|c|c|c|c|c|}
\hline \multirow[t]{2}{*}{ Molecular markers } & & \multirow[t]{2}{*}{$\mathrm{N}$} & \multicolumn{2}{|c|}{ Therapeutic effect } & \multirow[t]{2}{*}{$\chi^{2}$} & \multirow[t]{2}{*}{$\mathrm{P}$} \\
\hline & & & $\mathrm{CR}+\mathrm{PR}(\mathrm{N}, \%)$ & $\mathrm{NC}+\mathrm{PD}(\mathrm{N}, \%)$ & & \\
\hline \multirow[t]{2}{*}{ ES } & Positive & 66 & $43(65.15)$ & $23(34.85)$ & \multirow[t]{2}{*}{0.545} & \multirow[t]{2}{*}{0.599} \\
\hline & Negative & 62 & $34(54.84)$ & $28(45.16)$ & & \\
\hline \multirow[t]{2}{*}{ EGFR } & Positive & 77 & $52(67.53)$ & $25(32.47)$ & \multirow[t]{2}{*}{2.303} & \multirow[t]{2}{*}{0.177} \\
\hline & Negative & 51 & $25(49.02)$ & $26(50.98)$ & & \\
\hline \multirow[t]{2}{*}{ NF-кBp } & Positive & 68 & $37(54.41)$ & $31(45.59)$ & \multirow[t]{2}{*}{0.712} & \multirow[t]{2}{*}{0.44} \\
\hline & Negative & 60 & $39(65.00)$ & $21(35.00)$ & & \\
\hline \multirow[t]{2}{*}{ HER-2 } & Positive & 43 & $22(51.16)$ & $21(48.84)$ & \multirow[t]{2}{*}{1.25} & \multirow[t]{2}{*}{0.28} \\
\hline & Negative & 85 & $55(64.71)$ & $30(35.29)$ & & \\
\hline \multirow[t]{2}{*}{ VEGF } & Positive & 53 & $23(43.40)$ & $30(56.60)$ & \multirow[t]{2}{*}{5.659} & \multirow[t]{2}{*}{0.03} \\
\hline & Negative & 75 & $56(74.67)$ & $19(25.33)$ & & \\
\hline
\end{tabular}

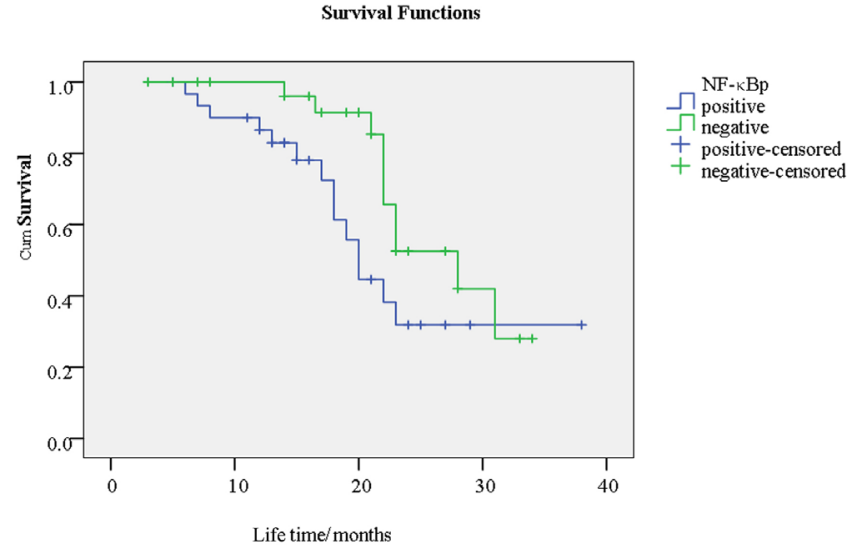

Figure 2. Comparison of life time between the patients with positive expression of NF-kBp and the patients with negative expression of $\mathrm{NF}-\kappa \mathrm{Bp}$. 


\section{DISCUSSION}

VEGF is a specific endothelial cell-stimulating factor (Sato et al., 1999). At present, some studies suggest that (Poon et al., 2001), to some extent, the serum levels of VEGF expression reflect the staging and prognosis of patients with esophageal cancer. In this study, our results showed that the serum levels of VEGF in patients with esophageal cancer were higher than that of normal controls, the protein expression of VEGF in tumor tissue was related to lymph node metastasis, and that the TNM stage and therapeutic effect of chemoradiotherapy were consistent with the results of relevant reports at home and abroad (Imdahl et al., 2002; Saintigny et al., 2007). VEGF expression may be one of the indicators reflecting the progress of esophageal cancer and is a potential predictor of the therapeutic effect. Shih et al. (2000) detected dynamic changes in the serum levels of VEGF in esophageal cancer patients who received chemoradiotherapy before operation and found that VEGF expression levels of patients were significantly higher than that of the control group; whereas 3 months after the surgery, the serum levels of VEGF of these patients were significantly lower. This indicated that serum VEGF expression is related to tumor load. Some studies also concluded that chemoradiotherapy can reduce serum levels of VEGF of patients with esophageal cancer (Ahn et al., 2002). Shimada et al. (2001) considered that the efficacy of chemotherapy and the survival time of esophageal cancer patients with low VEGF expression were superior to that of patients with high VEGF expression. Interestingly, our results found that serum levels of VEGF differed in the subjects from different nationalities, and that the levels in Han patients were higher compared with those in Uygur and Kazakh patients $(\mathrm{P}<0.05)$. However, VEGF expression in the tumor tissue showed the opposite trend. The expression in Han patients was lower compared to that in the Uygur and Kazakh patients, without significant statistical difference $(P>0.05)$, which suggested that the serum and tissue levels of the same marker may be inconsistent.

EGFR is an expression product of the proto-oncogene c-erbB1 and a member of the EGFR family. EGFR is overexpressed in a variety of tumor cells. The overexpression of one or more of the EGFR family receptors appeared in about $60 \%$ of cancer patients, and this abnormal expression is related to angiogenesis, invasion, metastasis, and anti-apoptosis of tumors (Nicholson et al., 2001). Our results showed that the serum and tumor tissue expressions of EGFR protein of esophageal squamous cell carcinoma patients were higher than those of the normal group. EGFR protein expressions in male patients were higher than that of female patients $(\mathrm{P}<0.05)$, which may be due to the small sample size used in this study or gender differences in EGFR expression. Our results did not show that the expression of EGFR had a relationship with nationality, pathological differentiation, clinical stage, chemoradiotherapy, and other clinical pathological factors. Some results showed that EGFR protein expression is correlated with the $\mathrm{T}$ stage, depth of invasion, lymph node metastasis, pathological stage, and prognosis of patients (Wang et al., 2007). EGFR is a potential predictor of the effect of chemoradiotherapy on esophageal cancer (Delektorskaya et al., 2009). However, some results showed that protein expression or mutation in the EGFR gene had no predictive value for the efficacy of chemoradiotherapy for esophageal cancer (Gibson et al., 2003). Thus, whether EGFR can be considered as one of the predictors of esophageal cancer still needs to be further studied.

Some studies confirmed that HER-2/neu gene amplification or overexpression can occur in about $30 \%$ of human malignancies, including breast cancer, stomach cancer, ovarian 
cancer, endometrial cancer, prostate cancer, and other endothelium-derived tumors (Sato-Kuwabara et al., 2009). It suggested that the overexpression of the HER-2/neu gene has a certain relevance to the generation of these tumors. HER-2/neu is one of a few biological predictors applicable in assessing the clinical efficacy of targeted treatment for cancers such as breast cancer and gastric cancer (Thompson et al., 2011). NCCN esophageal cancer guidelines in 2011 mentioned that for esophageal cancer patients with local recurrence or distant metastasis, HER-2/neu should be routinely detected, by immunohistochemistry and FISH. The strong expression of HER-2/neu can be detected by immunohistochemistry and further confirmed by FISH (Brücher et al., 2006). It has been suggested that the strong expression of HER-2/neu is an indication for using Mabthera in the treatment (Bang et al., 2010). Therefore, the detection of HER-2/neu protein and gene can be used to determine the therapeutic effect of esophageal cancer patients receiving Mabthera treatment. In this study, our results found that the expression of HER-2 in patients with esophageal squamous cell carcinoma in Xinjiang were negatively correlated with the differentiation of tumor cells, which suggested that HER-2 could be used to determine the prognosis of esophageal cancer. The results of this study did not show that it has a relationship with the therapeutic effect of esophageal cancer.

Amicine is a protein that was isolated from the culture supernatants of mouse hemangioendothelioma. $\mathrm{N}$-terminal amino acid sequencing showed that the substance is a terminal fragment of collagen x VII, and is called endostatin. Large numbers of experimental studies have shown that endostatin has a strong inhibitory effect on tumor growth and metastasis (Dhanabal et al., 1999). It is expressed in lung cancer, esophageal cancer, and other tumor tissues. We found that the endostatin levels of patients with esophageal cancer among different nationalities in Xinjiang were different. Endostatin levels in Han patients were higher than those in Kazakh and Uygur patients, while there was no relationship with the clinical stage, pathological differentiation, and other clinical pathological factors. Serum levels of endostatin of patients with esophageal squamous cell carcinoma before and after treatment were higher than those of the normal group, which suggested that serum levels of endostatin were increased in patients with esophageal squamous cell carcinoma. Whether endostatin can be a biomarker for the diagnosis of esophageal cancer should be further studied.

$\mathrm{NF}-\kappa \mathrm{B}$ is a pleiotrophic nuclear transcription factor that is widely present in the human body. It can induce oncogenesis by upregulating the expression of cyclin D1 to result in infinite cell proliferation and to inhibit the transduction of the cell death signal. A large number of studies have shown (Schmitt and Lowe, 2002) that NF- $\kappa B$ protein expression has a relationship with the occurrence and development of a variety of tumors. Some studies suggested that the abnormal expression of NF- $\mathrm{KB}$ in esophageal cancer is a potential indicator of the sensitivity of chemotherapy (Abdel-Latif et al., 2004). The results of this study showed that the median survival time of patients with esophageal squamous cell carcinoma tissue with $\mathrm{NF}-\kappa \mathrm{B}$ protein expression and negative expression was 20 and 26 months, respectively, which suggested that NF- $\mathrm{kBp}$ protein expression may be an indicator to determine therapeutic effect in case of esophageal squamous cell carcinoma.

At present, the relevant literature on the combined use of ELISA and immunohistochemistry to detect tumor markers is limited. Research suggests that some serum tumor markers to detect esophageal cancer patients show the clinical significance of treatment, while the expression of some of the serum tumor markers (VEGF, ES) differ in Han, Uygur, and Kazakh patients in Xinjiang. 


\section{ACKNOWLEDGMENTS}

Research supported by the Natural Science Foundation of Xinjiang Uygur Autonomous Region (\#2010211A47).

\section{REFERENCES}

Abdel-Latif MM, O'Riordan J, Windle HJ, Carton E, et al. (2004). NF-kappaB activation in esophageal adenocarcinoma: relationship to Barrett's metaplasia, survival, and response to neoadjuvant chemoradiotherapy. Ann. Surg. 239: 491500.

Ahn MJ, Jang SJ, Park YW, Choi JH, et al. (2002). Clinical prognostic values of vascular endothelial growth factor, microvessel density, and p53 expression in esophageal carcinomas. J. Korean Med. Sci. 17: 201-207.

Bang YJ, Van Cutsem E, Feyereislova A, Chung HC, et al. (2010). Trastuzumab in combination with chemotherapy versus chemotherapy alone for treatment of HER2-positive advanced gastric or gastro-oesophageal junction cancer (ToGA): a phase 3, open-label, randomised controlled trial. Lancet 376: 687-697.

Brücher BL, Becker K, Lordick F, Fink U, et al. (2006). The clinical impact of histopathologic response assessment by residual tumor cell quantification in esophageal squamous cell carcinomas. Cancer 106: 2119-2127.

Delektorskaya VV, Chemeris GY, Kononets PV and Grigorchuk AY (2009). Clinical significance of hyperexpression of epidermal growth factor receptors (EGFR and HER-2) in esophageal squamous cell carcinoma. Bull. Exp. Biol. Med. 148: 241-245.

Dhanabal M, Ramchandran R, Waterman MJ, Lu H, et al. (1999). Endostatin induces endothelial cell apoptosis. J. Biol. Chem. 274: 11721-11726.

Geldart T and Astras G (2011). Isolated CNS relapse in human epidermal growth factor receptor 2-positive esophagogastric cancer: effective treatment with trastuzumab after failure of surgery and radiotherapy. J. Clin. Oncol. 29: e664-e665.

Gibson MK, Abraham SC, Wu TT, Burtness B, et al. (2003). Epidermal growth factor receptor, p53 mutation, and pathological response predict survival in patients with locally advanced esophageal cancer treated with preoperative chemoradiotherapy. Clin. Cancer Res. 9: 6461-6468.

Hildebrandt MA, Yang H, Hung MC, Izzo JG, et al. (2009). Genetic variations in the PI3K/PTEN/AKT/mTOR pathway are associated with clinical outcomes in esophageal cancer patients treated with chemoradiotherapy. J. Clin. Oncol. 27: 857-871.

Imdahl A, Bognar G, Schulte-Monting J, Schoffel U, et al. (2002). Predictive factors for response to neoadjuvant therapy in patients with oesophageal cancer. Eur. J. Cardiothorac. Surg. 21: 657-663.

Jemal A, Clegg LX, Ward E, Ries LA, et al. (2004). Annual report to the nation on the status of cancer, 1975-2001, with a special feature regarding survival. Cancer 101: 3-27.

Kairakbaev MK (1978). Malignant neoplasms among ethnic groups in the Kazakh SSR. Vopr. Onkol. 24: 100-104.

Liu L, Wu C, Wang Y, Zhong R, et al. (2011a). Association of candidate genetic variations with gastric cardia adenocarcinoma in Chinese population: a multiple interaction analysis. Carcinogenesis 32: 336-342.

Liu Z, Feng JG, Tuersun A, Liu T, et al. (2011b). Proteomic identification of differentially-expressed proteins in esophageal cancer in three ethnic groups in Xinjiang. Mol. Biol. Rep. 38: 3261-3269.

Luthra R, Wu TT, Luthra MG, Izzo J, et al. (2006). Gene expression profiling of localized esophageal carcinomas: association with pathologic response to preoperative chemoradiation. J. Clin. Oncol. 24: 259-267.

Nicholson RI, Gee JM and Harper ME (2001). EGFR and cancer prognosis. Eur. J. Cancer 37 (Suppl 4): S9-15.

Poon RT, Fan ST and Wong J (2001). Clinical implications of circulating angiogenic factors in cancer patients. J. Clin. Oncol. 19: 1207-1225.

Saintigny P, Kambouchner M, Ly M, Gomes N, et al. (2007). Vascular endothelial growth factor-C and its receptor VEGFR-3 in non-small-cell lung cancer: concurrent expression in cancer cells from primary tumour and metastatic lymph node. Lung Cancer 58: 205-213.

Sato-Kuwabara Y, Neves JI, Fregnani JH, Sallum RA, et al. (2009). Evaluation of gene amplification and protein expression of HER-2/neu in esophageal squamous cell carcinoma using fluorescence in situ hybridization (FISH) and immunohistochemistry. BMC Cancer 9: 6.

Sato F, Shimada Y, Watanabe G, Uchida S, et al. (1999). Expression of vascular endothelial growth factor, matrix metalloproteinase-9 and E-cadherin in the process of lymph node metastasis in oesophageal cancer. $\mathrm{Br}$. J. Cancer 80: 1366-1372.

Schmitt CA and Lowe SW (2002). Apoptosis and chemoresistance in transgenic cancer models. J. Mol. Med. 80: 137-146. 
Shih CH, Ozawa S, Ando N, Ueda M, et al. (2000). Vascular endothelial growth factor expression predicts outcome and lymph node metastasis in squamous cell carcinoma of the esophagus. Clin. Cancer Res. 6: 1161-1168.

Shimada H, Takeda A, Nabeya Y, Okazumi SI, et al. (2001). Clinical significance of serum vascular endothelial growth factor in esophageal squamous cell carcinoma. Cancer 92: 663-669.

Thompson SK, Sullivan TR, Davies R and Ruszkiewicz AR (2011). Her-2/neu gene amplification in esophageal adenocarcinoma and its influence on survival. Ann. Surg. Oncol. 18: 2010-2017.

Wang KL, Wu TT, Choi IS, Wang H, et al. (2007). Expression of epidermal growth factor receptor in esophageal and esophagogastric junction adenocarcinomas: association with poor outcome. Cancer 109: 658-667.

Ychou M, Boige V, Pignon JP, Conroy T, et al. (2011). Perioperative chemotherapy compared with surgery alone for resectable gastroesophageal adenocarcinoma: an FNCLCC and FFCD multicenter phase III trial. J. Clin. Oncol. 29: $1715-1721$. 